\title{
Sistema diacrítico e transcendência em Merleau-Ponty
}

\section{Diacritical system and transcendence in Merleau-Ponty}

Jeovane Camargo

Doutor em filosofia pela UFSCAR

Resumo: A investigação do sentido diacrítico da linguagem leva a se entender a estrutura perceptiva como um arranjo opositivo não mais dependente exclusivamente das possibilidades do corpo. Esse ajuste teórico da segunda fase do pensamento de Merleau-Ponty visa a superar os problemas da primeira fase. O percebido e a fala significam agora por meio do arranjo de seus termos, não remetendo seu poder expressivo a algum tipo de positividade ou "interioridade".

Palavras-chave: linguagem, sistema diacrítico, percepção.

Abstract: The investigation of the diacritical meaning of language leads to understand the perceptive structure as an oppositional arrangement no longer dependent exclusively on the possibilities of the body. This theoretical adjustment of the second phase of Merleau-Ponty's thought aims to overcome the problems of the first phase. Perception and speech now signify through the arrangement of their terms, not by referring their expressive power to some kind of positivity or "interiority".

Keywords: language, diacritical meaning, perception. 


\section{Sistema diacrítico e transcendência}

To período intermediário de seu pensamento, Merleau-Pon1 ty se preocupa em desenvolver uma nova concepção da linguagem e dos atos de expressão, de tal modo que essa reformulação amplie-se até envolver a concepção da percepção. Ao adotar e ao alargar o pensamento de Saussure, Merleau-Ponty encontra no sistema diacrítico a estrutura da linguagem. Para não recair no prejuízo intelectualista de uma consciência por detrás da linguagem e nem na crítica de nomenclaturismo, de que o sentido gestual das palavras traduziria certas atitudes do corpo em face das coisas, Merleau-Ponty argumenta que cada vocábulo não significa isoladamente ou por referência a algo no mundo, ao qual ele corresponderia ou traduziria. Tomadas isoladamente, as palavras não possuem significações que possam ser separadas do conjunto de vocábulos e de expressões que formam a língua. A análise da linguística de Saussure auxilia Merleau-Ponty a descobrir o sistema opositivo da língua, de modo que as palavras significam diferenciando-se umas das outras. Essa nova concepção representa uma crucial transformação em relação à Fenomenologia da percepção (1945), posto que nesta a linguagem era ou a expressão de pensamentos já feitos, de uma consciência por trás da linguagem (prejuízo intelectualista) ou a tradução das atitudes típicas do corpo anônimo em sua relação com as coisas (nomenclaturismo), tal como foi visto no primeiro capítulo. Com a linguística de Saussure, Merleau-Ponty percebe que as palavras significam graças às relações de umas com as outras, e não por corresponder a certa realidade já dada ou pré-determinada. Assim, cada língua é um sistema opositivo que não corresponde a qualquer realidade prévia. Não possuindo uma realidade pré-determinada, cada língua constitui-se arbitrariamente, segundo as oposições de seus signos. Elas não poderiam, portanto, ser originadas por convenção, hipótese que suporia uma linguagem prévia e uma realidade já dada em relação à qual as convenções seriam estabelecidas. Tal sistema opositivo é trazido também para o âmbito da percepção, de modo que a experiência não é mais fornecida pela relação imediata entre os poderes do corpo e o 
mundo. Há uma organização opositiva das coisas, de maneira que a diferenciação entre elas constitui a cada momento o sentido experimentado pelo sujeito perceptivo. Desse modo, ao invés de a experiência ser definida pelos dados fornecidos pelo movimento do corpo anônimo, isto é, pelo contato imediato dos esquemas corporais com o mundo, ela passa a ser pensada como o contato indireto com certo sistema opositivo das próprias coisas. O corpo não traz a temporalidade e a significação para o seio do mundo, mas reconstrói expressivamente o sistema opositivo das coisas. A relação entre corpo e mundo deixa de ser direta, imediata, e passa a ser indireta, a reconstrução expressiva do sistema de oposições que constitui o mundo.

Essa interpretação é um dos melhores meios para se entender por que, nos anos de 1950, Merleau-Ponty se dedica ao tema da linguagem e à linguística de Saussure, pois, por meio dela, pode-se entender a investigação da linguagem como o caminho metodológico necessário para se chegar às concepções de ser mais decisivas e elaboradas da última fase. Graças à descoberta do sistema diacrítico na estrutura da linguagem, Merleau-Ponty teria conseguido elaborar uma nova concepção de ser, o "ser bruto", ou carne. Este possui uma organização própria da/na qual o corpo emerge. Ao contrário da Fenomenologia da percepção, na qual o ser era reduzido àquilo que pode ser apreendido pelo aparato corporal, o que se afirma agora é que o ser possui uma sensibilidade própria que não depende do corpo para se constituir.

Ao lado do sistema diacrítico presente nas próprias coisas e na linguagem - caráter que torna indireto o acesso ao ser, posto que não há mais relação imediata entre esquemas corporais e mundo nem a expressão verbal de uma ordem prédeterminada, senão que recriação de conjuntos de relações opositivas - reaparece a temporalidade, uma produtividade ou uma transcendência no âmago dos acontecimentos expressivos. Há então uma sucessão ou passagem que se realiza no interior do sistema diacrítico, do ser ou da natureza. Desde que a temporalidade não desaparece no período intermediário, e desde que o funcionamento da ordem perceptiva e da ordem 
linguística tem como fundamento a estrutura temporal, cabe ver como esta realiza a articulação entre percepção e linguagem. É preciso investigar qual novidade o sistema diacrítico, vindo da linguística de Saussure, trouxe para os problemas deixados pela obra de 1945, mas sem deixar de notar que a estrutura temporal reaparece nos textos da fase intermediária. Buscar-se-á analisar assim como a "fecundidade" do tempo, sua "iniciativa própria", sua "exigência de sucessão", pode "alimentar" o surgimento de significações novas no seio das relações opositivas que constituem cada sistema linguístico. Em vista disso, procurar-se-á mostrar, primeiro, em que sentido a estrutura temporal permanece no período intermediário como o critério ontológico de compreensão das descrições apresentadas; segundo, se a experiência se oferece originariamente de modo silencioso ou já linguístico; e, terceiro, o avanço obtido em relação aos prejuízos da obra de 1945.

Na passagem da Fenomenologia da percepção aos textos que procuram elaborar uma fenomenologia da linguagem, notase que a estrutura básica de funcionamento da temporalidade, ou das relações de motivação, permanece em sua forma elementar. Tal como em 1945 o novo utilizava-se do já adquirido para poder se apresentar, em A linguagem indireta e as vozes do silêncio (1952) a nova significação surge como uma reorganização das significações já constituídas. O sentido inédito se forma por meio da reorganização de falas sedimentadas, assim como a fala falante surgia pelo rearranjo das falas faladas e também como um presente novo só podia se manifestar pela retomada criativa de seu passado, ou apoiando-se em seu passado. Todavia, em A linguagem indireta e as vozes do silêncio, Merleau-Ponty argumenta que a significação se realiza na relação dos signos uns com os outros, não estando encerrada em cada um dos signos tomados individualmente: "cada ato de expressão torna-se significante apenas como modulação de um sistema geral de expressão e na medida em que se diferencia dos outros gestos linguísticos" (MERLEAU -PONTY, 2004, p. 132). Essa concepção não estava presente na primeira fase, posto que então se fazia o elogio do Cogito tácito como o silêncio por trás das significações, o foco onde elas se integrariam, relacionando-se e articulando-se entre si. 


\section{Sistema diacrítico e intenção significativa}

O texto Sobre a fenomenologia da linguagem foi apresentado pela primeira vez em Bruxelas, no I Colóquio Internacional de Fenomenologia, em 1951. Nesse texto, Merleau-Ponty procura se distanciar da ideia de uma linguagem universal (tal qual queria Husserl nas Logische Untersuchungen) sem cair em certo psicologismo, cuja matéria de estudo seria a experiência da língua. Para reencontrar a "fecundidade da expressão", Merleau-Ponty propõe então um alargamento da linguística de Saussure. Este havia ainda oposto sistema sincrônico e sistema diacrônico, o primeiro representando a língua falada e o segundo a história da língua, de modo que não haveria relação entre os dois saberes. Por sua vez, ao propor uma fenomenologia da fala, Merleau-Ponty quer estabelecer a comunicação entre estas disciplinas. Nesse sentido, primeiro ele afirma que a "sincronia envolve a diacronia" (MERLEAU-PONTY, 2010, p. 1190). Isso significa que, apesar de todos os acasos, deslizes de sentido e outros fatos fortuitos que constituem uma língua ao longo da história, houve sempre, em cada momento ("corte transversal"), uma "lógica interna" da língua (MERLEAU-PONTY, 2010, p. 1191). Segundo, a "diacronia envolve a sincronia", o que quer dizer que o sistema sincrônico comporta fendas, lacunas, que ele não significa sem equívoco, de modo que, por meio delas, novas lógicas linguísticas surgem. Desse modo, a fala é sincrônica e a língua diacrônica. Tal dialética explica a transformação de uma língua em outra, tal como aconteceu na passagem do sistema de declinação e flexão do latim para o sistema da língua francesa, baseado na preposição. E também explica a especificidade de cada língua frente às demais. No interior de uma língua, os signos que exprimem ideias semelhantes limitam-se entre si: a área de ação da palavra mouton (carneiro) em francês não é a mesma que a de mutton em inglês, pois em inglês mouton corresponde a sheep e mutton designa a carne de carneiro. As relações se estabelecem entre a cadeia verbal e o universo que elas significam (Cf. MERLEAU-PONTY, 1988, p. 83), não reenviando a um sistema significativo primeiro. Ao relacionar sistema sincrônico e sistema diacrônico, Merleau-Ponty reencontra a "fecundidade da expressão" e escapa da linguagem universal - a qual, ao vincular cada 
signo a uma significação, tornava a linguagem o lembrete ou o substituto do pensamento - ao mesmo tempo em que escapa do psicologismo, o qual trataria a língua apenas enquanto experiência do sujeito falante. Segundo a dialética entre diacronia e sincronia, a língua possui a cada momento uma "lógica atual" ou "lógica interna" que comporta "mudanças latentes" ou "em incubação" (MERLEAU-PONTY, 2010, p. 1191). As palavras, tomadas isoladamente, deixam de corresponder a significações pré -linguísticas. Elas significam, enfim, por certo "valor de emprego" ou "valor expressivo" (MERLEAU-PONTY, 2010, p. 1191, 1192). Esse valor não é determinado pela soma dos valores de cada vocábulo presente na língua. Ao contrário, o valor expressivo é fornecido pelas oposições dos signos entre si, de forma que cada signo "significa apenas sua diferença frente ao outros" (MERLEAU-PONTY, 2010, p. 1192). Isso quer dizer que só há identidade na diferença, não havendo identidades que, por serem idênticas a si mesmas, diferenciar-se-iam de outras. No sistema opositivo, cada palavra encontra seu valor expressivo ao diferenciar-se das outras palavras. Nesse sentido, em "cada língua só há diferenças de significações" (MERLEAU-PONTY, 2010, p. 1192) e não significações que as palavras substituiriam.

A “intenção significativa", por sua vez, não se representa tematicamente os meios de comunicação e então os compara com aquilo que ela quer exprimir. Não há uma significação a ser expressa e então a escolha dos meios para exprimi-la. Ao contrário, tal como o corpo possui consciência da paisagem a sua volta sem representar-se cada um dos objetos que a compõem, a intenção significativa é conduzida por certo "estilo da fala". Tal "estilo da fala", ou "significação 'linguageira' da linguagem" (MERLEAU-PONTY, 2010, p. 1193) realiza a "mediação entre a intenção ainda muda" e os meios expressivos. Note-se que Merleau-Ponty não afirma a existência de significações prévias ou de uma consciência silenciosa das significações, posto que "exprimir é tomar consciência" (MERLEAU-PONTY, 2010, p. 1195), não existindo assim qualquer pensamento anterior à expressão. No entanto, a intenção significativa é "dependente" do "eu posso", ela é "um caso eminente da intencionalidade corporal" (MERLEAU-PONTY, 2010, p. 1193). O estilo da fala ou sua significação 
"linguageira" são o sistema opositivo da língua, o qual permite o aparecimento de novos arranjos, já que em sua sincronia aparecem fendas por meio das quais novos sistemas podem aparecer. A fala significa indiretamente, sem corresponder a dados prévios sejam da consciência sejam da experiência sensível. Esta também é organizada segundo o sistema opositivo descoberto pela análise da linguagem. Contudo, como compreender que a intenção significativa seja ainda dependente e uma "assinalada" modalidade da intencionalidade corporal?

Tal como o mundo anima o corpo a realizar determinada tomada perceptiva, posto que o corpo responde aos acontecimentos do mundo, o sistema opositivo dos signos, através de suas fendas e lacunas, exigiria da intencionalidade expressiva uma nova significação. Há uma "surda presença" desse sistema opositivo, o qual solicita a todo momento certo posicionamento do falante. Assim como o corpo opera em um "mundo pré-constituído" (MERLEAU-PONTY, 2010, p. 1199), a intenção significativa opera em uma determinada ordem significativa, a da língua. Há um fenômeno de "transgressão intencional" (MERLEAU-PONTY, 2010, p. 1199), no qual o corpo não constitui outrem, os objetos ou aquilo que ele quer expressar, senão que ele é "investido" ou "convocado" por aquilo mesmo que ele quer significar. Por isso, Merleau-Ponty apresenta a ideia de uma "espontaneidade ensinante" (MERLEAU-PONTY, 2010, p. 1199), já que o corpo não possui as significações que ele quer exprimir, mas as aprende no momento mesmo em que as expressa. Existe assim uma dialética entre intenção e solicitação, visada e resposta, eu e outrem.

Alguns textos de A prosa do mundo (1950-1951) explicam de modo mais suficiente a relação entre intencionalidade corporal e expressão linguística. Em A ciência e a experiência da expressão, procura-se explicitar o que constitui a especificidade da fala falante. Ao contrário da fala falada, a qual diz respeito às construções habituais e sedimentadas de uma língua que são já conhecidas e repetidas cotidianamente, a fala falante é a manifestação de uma significação inédita, diferente e desconhecida em relação às construções cristalizadas da cultura. 
A significação nova não é uma construção ex nihilo, ela não vem do nada; antes, ela reorganiza as construções habituais, as falas sedimentadas. Entretanto, qual poder realiza a passagem das significações cristalizadas às novas significações? Por que se passa das sedimentações da cultura às falas inéditas? $\mathrm{O}$ que, enfim, constitui a produtividade da fala, manifesta nas reconfigurações operadas pela fala falante? Para responder essa questão, Merleau-Ponty procura explicitar a relação entre linguagem e percepção.

As coisas percebidas nunca se oferecem inteiramente, mas como inacabadas e inesgotáveis. Elas possuem um ar de eternidade porque nenhuma inspeção pode abarcá-las inteiramente (MERLEAU-PONTY, 2002, p. 59-60). A coisa percebida é a contração, no presente (atual), de uma série de possibilidades perceptivas cuja explicitação total não pode ser realizada. Como diz $O$ algoritmo e o mistério da linguagem, a "explicitação da coisa iria ao infinito" (MERLEAU-PONTY, 2002, p. 155). Isso acontece porque "cada vetor do espetáculo percebido estabelece, para além de seu aspecto momentâneo, o princípio de certas equivalências nas variações possíveis do espetáculo [...]" (MERLEAU-PONTY, 2002, p. 157). A configuração perceptiva é um campo sensível que se manifesta segundo um estilo geral de ser. Cada arranjo possui um valor prático, é um fazer segundo as relações do "eu posso" com o mundo. Tal como na Fenomenologia da percepção, a unidade da coisa não é real, posto que a coisa não é uma identidade, um objeto puro, mas presuntiva, isto é, a perspectiva assumida quer se passar pelo todo, presumindo acabada uma explicitação que não pode ser concluída.

Da mesma maneira, a significação linguística não é uma essência ou ideia pura, ou seja, o que é dito não é dito de modo absoluto, completo e definitivo. Assim que é proferida, a significação possui um valor de uso, mas ela é ao mesmo tempo insuficiente (Cf. MERLEAU-PONTY, 2002, p. 58). Ela pretende consumar a linguagem, ser uma fala que conclua tudo, mas essa eternidade é apenas presumida (Cf. MERLEAU -PONTY, 2002, p. 63, 65). Por isso, Merleau-Ponty afirma que "uma expressão consumada é quimérica" (MERLEAU-PONTY, 
2002, p. 51). Isso acontece porque cada significação, cada valor de emprego de um signo faz parte de um sistema, porque cada signo e cada emprego deste se oferecem segundo sua coexistência com outros signos. A significação é um "sentido lateral ou oblíquo que resulta do comércio das próprias palavras (ou das significações disponíveis)" (MERLEAU-PONTY, 2002, p. 69).

Tanto a percepção como a linguagem são sistemas diacríticos, arranjos momentâneos nos quais ressoam outras possibilidades expressivas; ambas são configurações frequentadas por outras variantes. O possível, comenta Merleau-Ponty, é o "aparecimento lateral de um aparelho de sentido que só aos poucos manifesta seu sentido" (MERLEAU-PONTY, 2002, p. 69, nota *). A percepção e a linguagem realizam-se segundo uma mesma lógica, um mesmo Logos, uma mesma estrutura, uma mesma transcendência ou espessura temporal: ambas superam o já constituído retomando-o, integrando-o em uma nova significação ou nova configuração ${ }^{28}$.

A percepção abre-se a um mundo já constituído e então o reconstitui (MERLEAU-PONTY, 2002, p. 156-157; grifo meu). Contudo, esse mundo já constituído, essa "pré-existência do mundo" diz respeito a um sujeito já "envolvido no ser por campos perceptivos, por 'sentidos"' (MERLEAU-PONTY, 2002, p. 155), de modo que o percebido parece pré-existir à percepção. A percepção reconstitui o campo perceptivo oferecido pelos sentidos. Há uma transcendência ou espessura temporal já em operação e que o sujeito retoma ao assumir determinada postura ou tomada perceptiva: "Por mais firme que seja minha apreensão perceptiva do mundo, ela é totalmente dependente do movimento centrífugo que me lança a ele [...]" (MERLEAU

$28 \quad$ Também o algoritmo reproduz essa estrutura: "O essencial do pensamento matemático [...] está nesse momento em que uma estrutura se descentra, abre-se a uma interrogação, e reorganiza-se segundo um sentido novo que não obstante é o sentido dessa mesma estrutura" (MERLEAU-PONTY, 2002, p. 159). Se a expressão algorítmica é exata e parece repousar em si mesma como uma essência, é "por causa da exata equivalência que ela estabelece entre relações dadas e as que delas se conclui" (MERLEAU-PONTY, 2002, p. 160). Do mesmo modo que, assim que se expressa uma significação, esquece-se o processo de reestruturação que levou a ela e acredita-se em sua pré-existência, também se esquece o devir do conhecimento matemático. 
-PONTY, 2002, p. 157; grifo meu). A mesma estrutura reaparece na análise da linguagem. Por um lado, a fala falante é uma reconfiguração das falas já constituídas, uma diferenciação em relação àquilo que a precede. Por outro, a linguagem é uma "sublimação que conserva e transforma o mundo percebido no mundo falado" (MERLEAU-PONTY, 2002, p. 156). Percepção e fala manifestam uma mesma estrutura, ambas são "ávidas de mudança", ambas são um "mover-se da reestruturação" (MERLEAU-PONTY, 2002, p. 58, 161). As duas ordens apresentam uma transcendência que precisa sempre passar adiante, ir além, um mover-se cujas manifestações se suprimem à medida que se propagam, e se anulam se não se propagam ${ }^{29}$ (Cf. MERLEAU -PONTY, 2002, p. 58). Uma transcendência em que cada presente é diferenciação em relação ao precedente (MERLEAU-PONTY, 2002, p. 59, nota *), em que há também uma "imanência do novo no antigo" (MERLEAU-PONTY, 2002, p. 152). Elas se estruturam como uma transformação que conserva, uma reestruturação que integra a estrutura precedente.

A transcendência da percepção e da linguagem vem de sua própria organização (Cf. MERLEAU-PONTY, 2002, p. 60, nota *). Há um ultrapassar-se do gesto na apreensão perceptiva: "Não se pode imitar a voz de alguém sem retomar alguma coisa de sua fisionomia e [...] de seu estilo pessoal" (MERLEAU-PONTY, 2002, p. 34). E há também um ultrapassar-se do gesto linguístico: "É preciso que ela própria [a fala] ensine seu sentido [...], não basta que assinale um sentido já possuído de parte a parte [...]; portanto, é-lhe essencial ultrapassar-se como gesto, ela é o gesto que se suprime como tal e se ultrapassa em direção ao sentido" (MERLEAU-PONTY, 2002, p. 175). Há uma transcendência do sentido em relação ao signo, da significação em relação à linguagem, assim como há uma transcendência da coisa em relação aos conteúdos sensíveis oferecidos pelos sentidos e do outro em relação àquilo que eu apreendo. O gesto corporal e o gesto linguístico configuram-se como Gestalt, como um presente em um campo de outros variantes possíveis,

$29 \quad$ Segundo a estrutura da transcendência, só há significação por um movimento que ultrapassa toda significação (Cf. MERLEAU-PONTY, 2002, p. 176). 
um presente frequentado por outras possibilidades de configuração, algo expresso e algo não expresso (Cf. MERLEAU-PONTY, 2002, p. 60, nota **).

No entanto, essa transcendência da significação devese também à vontade de se comunicar dos sujeitos falantes: "Quaisquer que sejam os acasos e as confusões que o francês percorreu em sua trajetória [...], o fato é que falamos e dialogamos, esse caos é retomado em nossa vontade de nos exprimirmos e de [nos] compreendermos [...]" (MERLEAU -PONTY, 2002, p. 45) ${ }^{30}$. A intenção de se comunicar é, nesse nível $^{31}$, linguística, como defende Moutinho (Cf. MOUTINHO,

30 "O que sustenta a invenção de um novo meio de expressão é, portanto, o ímpeto dos sujeitos falantes que querem se compreender e que retomam como uma nova maneira de falar os restos gastos de um outro modo de expressão" (MERLEAU-PONTY, 2002, p. 57).

$31 \quad$ O texto de Sobre a fenomenologia da linguagem parece também se perguntar pela origem da linguagem. Merleau-Ponty se pergunta: "Mas por que, como, em que sentido, estas [as significações cristalizadas] já estão disponíveis?" (MERLEAU-PONTY, 2010, p. 1195). Até então Merleau-Ponty havia explicado como uma intenção ainda muda se utiliza das falas constituídas, reorganiza-as, para assim possibilitar o surgimento ou a instituição de uma fala inédita. Agora, no entanto, ele lança uma nova questão: se as falas inéditas surgem por meio da reorganização de falas cristalizadas, como porém essas falas surgiram, para que uma intenção ainda muda pudesse utilizá-las? A questão agora parece interrogar pela origem da linguagem. A resposta a essa questão exigiria uma explicitação rigorosa a respeito do estatuto da intencionalidade, de modo a esclarecer se ela é originariamente predicativa ou antepredicativa. Todavia, Merleau-Ponty empreende nesse momento o mesmo desvio que ele já havia operado na Fenomenologia da percepção: as significações sedimentadas se tornaram disponíveis "quando, em seu tempo, foram instituídas como significações a que posso recorrer, que eu tenho — por uma operação expressiva do mesmo tipo" (MERLEAU-PONTY, 2010, p. 1195). Essa resposta não esclarece a origem da linguagem ou o estatuto da intencionalidade - embora o texto indique que é por uma operação de mesmo tipo, por uma mesma estrutura que se realiza a passagem de um âmbito a outro. Merleau-Ponty não pretende explicar nesse momento o estatuto da intencionalidade, senão que a continuar a explicitação a respeito do funcionamento da linguagem. Por meio da reorganização das significações cristalizadas na cultura, chegou-se a uma significação nova, uma significação foi instituída ou, a partir de uma série de possibilidades expressivas, uma determinada expressão se sedimentou. O tema da origem da linguagem desaparece e o assunto que surge em primeiro plano é o da passagem das significações já adquiridas às significações inéditas, ou a passagem de certo arranjos diacríticos a novos 
2006, p. 332). No diálogo, a fala do outro invade minhas significações e a minha fala invade as dele. Uma expressão inédita lança outrem e eu a uma significação que nem eu nem ele possuíamos. Essa produtividade da fala não pode, contudo, ser reduzida a um fenômeno gramatical, tal como queria Saussure, posto que assim a significação inédita apenas atualizaria significações já presentes, ainda que inconscientemente, no todo da língua. Como argumenta Ferraz, a escolha das novas significações depende do uso que uma comunidade faz de sua língua, dos modos pelos quais cada comunidade refere-se à realidade (Cf. FERRAZ, 2009, p. 74). A disparidade entre os patrimônios semânticos dos falantes motiva-os a procurarem se comunicar, a se fazerem compreender, de maneira que eles se direcionam às novas significações através das primeiras intenções esboçadas (Cf. FERRAZ, 2009, p. 71). É graças à transcendência, ao excesso de sentido do gesto expressivo que significações desconhecidas se anunciam e exigem do falante uma posição.

Esse poder da fala e do diálogo, entretanto, é um caso "assinalado", a modalidade mais elevada de um poder mais geral e originário. $\mathrm{O}$ poder que a fala possui de criar um mundo comum, um cultura, assenta-se sobre o modo de ser original da "sensibilidade ao mundo" ou da "corporeidade" (Cf. MERLEAU-PONTY, 2002, p. 173). A fala prolonga e transforma a relação antepredicativa do corpo com o mundo. Mas como um mundo comum e outrem aparecem nas relações não linguísticas do corpo com o exterior? Segundo Merleau-Ponty, há uma "universalidade do sentir" por meio da qual o sujeito conquista sua identidade e reconhece outrem. A relação do corpo com o mundo se realiza segundo um movimento único de passividade e atividade: há um impacto do mundo sobre o sujeito e ao mesmo tempo uma conquista do mundo pelo sujeito. Na relação de duplo sentido entre corpo e mundo, há uma configuração do campo que solicita respostas do sujeito, mas concomitantemente o campo percebido "arrasta ainda consigo [a] corporeidade", ele é influenciado pelos gestos do corpo sobre ele (Cf. MERLEAU-PONTY, 2002, p. 171). Acontece uma generalização do

arranjos. O texto, assim, não parece tratar de uma intencionalidade silenciosa, mas se concentra em explicitar o modo de funcionamento da linguagem. 
corpo. Isso quer dizer que a coisa se expõe segundo a maneira de o corpo a visar - embora ela possa, assim como a significação linguística, comportar relações não percebidas (Cf. MERLEAU-PONTY, 2002, p. 60-61, nota **). Outrem, por sua vez, manifesta-se como uma variante das possibilidades corporais, como uma das possibilidades de se assumir o campo perceptivo. Nas relações do corpo com o mundo aparece a possibilidade de uma outra percepção do mesmo ser, do mesmo campo de experiência. No interior do mundo individual, esboçam-se gestos semelhantes àqueles que o sujeito é capaz (Cf. MERLEAU-PONTY, 2002, p. 171, 172). A sensibilidade ao mundo, a sincronização corpo e coisas, enfim, a corporeidade mostra-se uma "significação transferível" e abre um mundo comum (Cf. MERLEAU-PONTY, 2002, p. 173).

No diálogo realiza-se algo análogo. O uso "geral" da fala, a comunicação, "supõe uma relação primordial de mim com minha fala que dá a ela o valor de uma dimensão do ser, participável por X" (MERLEAU-PONTY, 2002, p. 174). Isso significa que há uma generalidade da fala, uma comunidade do fazer linguístico por meio da qual as significações veiculadas solicitam-se e respondem-se: "A língua que falamos é algo como a corporeidade anônima [generalidade corporal] que partilho com os outros organismos" (MERLEAU-PONTY, 2002, p. 174). A sedimentação da cultura, um mundo cultural comum é possibilitado por essa transcendência da significação, pela capacidade de os signos ultrapassarem-se a si mesmos, de eles serem variantes, possibilidades de um sistema de comunicação (a língua) que pode ser assumido de diferentes maneiras por cada falante. Assim como não há sujeito absoluto ou objeto puro, senão que corpo e campo de experiência, uma transcendência dos gestos por meio da qual eles podem ser assumidos de outras maneiras por outros corpos, também não há significação pura, mas "sobre-significação", "sobre-sentido" (MERLEAU-PONTY, 2002, p. 179, 174-175, nota *), um ultrapassar-se do gesto expressivo, do signo, de maneira que ele manifesta-se como variante de um sistema linguístico, como poder de significar ainda algo outro, de ser assumido em uma significação diferente. 
A relação eu-outrem é de projeção e introjeção, uma relação de espelhamento a partir da qual pouco a pouco se desenham as identidades dos sujeitos. Quando escuta, o sujeito retoma ativamente a fala expressa por um outro, e, quando fala, ele escuta passivamente a significação que ele manifesta. Nos dois níveis, tanto na percepção como na fala, "o reconhecimento do passivo pelo ativo e do ativo pelo passivo, do receptor pelo locutor, é projeção e introjeção" (MERLEAU-PONTY, 2002, p. 41, nota *). Desde que a fala sublima a transcendência da ordem perceptiva, a possibilidade de projeção e introjeção é nela conservada. Como salienta Merleau-Ponty, a linguagem "está fundada no fenômeno do espelho ego-alter ego", na "generalidade carnal" ou na "fusão eu encarnado-mundo", ela transforma a coexistência com o mundo em coexistência de linguagem (MERLEAU-PONTY, 2002, p. 41-42, nota *). Movimento perceptivo e fala são ambos modalidades de uma mesma transcendência, "o que tenho de mais próprio, minha produtividade” (MERLEAU-PONTY, 2002, p. 176) ${ }^{32}$.

Nesse sentido, ao contrário do que supõe Carbone, a fala é um caso da intencionalidade corporal, e não algo como um ser próprio ou tal que só faça referência a ela mesma, como se a relação entre fala e língua fosse suficiente para fazer a passagem de uma significação à outra (CARBONE, 1993, os. 406, 411, 419). Há uma espessura temporal no interior do processo expressivo, uma transcendência que se transforma ou sublima em fala.

Há, contudo, uma especificidade do nível linguístico frente ao antepredicativo. No diálogo realiza-se a projeção-introjeção das significações porque a fala sublima a transcendência individual do sentir, das relações mudas entre corpo e mundo (Cf. MERLEAU-PONTY, 2002, p. 174-175). A corporeidade anônima, a sensibilidade ao mundo é individual porque ela é um movimento que não pode ainda retomar a si mesmo (Cf.

32 "Assim como, ao perceber um organismo que dirige gestos aos que o cercam, acabo por percebê-lo percebendo, porque a organização interna desses gestos é a mesma de minhas condutas e porque eles me falam de minha própria relação com o mundo, assim também, quando falo a um outro e o escuto, o que ouço vem inserir-se nos intervalos do que digo, minha fala coincide lateralmente com a de um outro [...]"(MERLEAU-PONTY, 2002, p. 176). 
MERLEAU-PONTY, 2002, p. 157), não pode se reconhecer como tal (Cf. MERLEAU-PONTY, 2002, p. 176). Ele apenas "mostra dados noutra parte aos nossos sentidos" (MERLEAU-PONTY, 2002, p. 175), isto é, ele é o transcender das Gestalten, o movimento centrífugo que lança ao mundo sem o afastamento que a fala traz. Esse distanciamento da fala permite uma retomada, um reconhecimento, porque ele é a criação de novas dimensões de significação: "Por mais firme que seja minha apreensão perceptiva do mundo, ela é totalmente dependente do movimento centrífugo que me lança a ele, e jamais o retomarei a menos que eu mesmo estabeleça, e espontaneamente, dimensões novas de significação" (MERLEAU-PONTY, 2002, p. 157; grifo meu). Enquanto a percepção só se interessa por relações imediatas, pelo "eco que o ser obtém dela mesma", a linguagem é "um esforço para recuperar, interiorizar, possuir verdadeiramente um sentido que escapa através da percepção ao mesmo tempo que nela se forma", isto é, a fala se interessa "pelo que faz ressoar", por aquilo que torna possível o eco, pelos termos das relações apresentadas na percepção (MERLEAU-PONTY, 2002, p. 156, 175). No nível antepredicativo, a coexistência eu-mundo-outrem é "puramente carnal, vital", isto é, limitada a relações imediatas, como conservação da vida e obtenção de satisfação. Já a linguagem é "criação de 'signos"', dimensões novas, afastamentos, reestruturações que integram o mundo mudo. "É num único movimento que o conhecimento se enraíza na percepção e dela se distingue" (MERLEAU-PONTY, 2002, p. 156).

A aproximação com a linguística de Saussure possibilita a Merleau-Ponty descobrir uma "transgressão intencional" entre corpo, mundo e outrem. O corpo não constitui seu campo de experiências, pois a experiência não mais se define pelo contato imediato entre os esquemas corporais e o mundo, senão como tomada expressiva de certo arranjo opositivo próprio dos dados sensíveis. Como diz Merleau-Ponty, "tudo se passa como se as funções da intencionalidade e do objeto intencional se encontrassem paradoxalmente trocadas" (MERLEAU-PONTY, 2010, p. 1199). As coisas sensíveis, assim como outrem e a fala, "convidam", "convocam" o corpo a dar uma resposta à sua configuração; eles o "investem" de certo campo significativo, 
ao mostrarem certa configuração em relação à qual o corpo precisa tomar posição.

O corpo realiza uma tomada expressiva em relação a dados sensíveis que escapam a seus poderes, em relação a algo autônomo face aos seus esquemas. Estes realizam uma reconstituição expressiva, significam indiretamente, posto que não há mais nenhum caráter imediato entre corpo e mundo, entre mundo e língua e mesmo entre língua e falante. Os textos da fase intermediária manifestam assim um processo de descentramento, procurando distanciar-se do idealismo subjetivista e do nomenclaturismo da Fenomenologia da percepção.

\section{A ordem da cultura e a espontaneidade}

Outro artigo do período intermediário fundamental para a compreensão do ajuste de pensamento empreendido por Merleau-Ponty, e também para se avaliar as respostas que ele encontrou para os problemas da Fenomenologia da percepção, é o texto intitulado A linguagem indireta e as vozes do silêncio (1952), ao lado da versão que o preparava: A linguagem indireta - redigida entre 1951-52 e publicada em A prosa do mundo (1969). Esses textos dão continuidade às teses de Sobre a fenomenologia da linguagem, estendendo-as à análise da literatura e da pintura.

Ao mostrar que tanto a percepção como a "gesticulação cultural" (MERLEAU-PONTY, 2004, p. 103) realizam-se segundo sistemas diacríticos, de maneira que a literatura e a pintura seriam a amplificação desse estado inicial, Merleau-Ponty se pergunta se o poder que a linguagem pretende ter de encerrar em um único ato uma série de atos de expressão não é o ponto mais alto de uma "acumulação tácita e implícita" já presente na pintura.

A linguagem opera por meio de uma "referência a si própria" (MERLEAU-PONTY, 2004, p. 72). Os signos não possuem significações prévias, em relação às quais eles seriam invólucros, mas significam pela diferença de sentido entre uns e outros. Desse modo, assegura Merleau-Ponty, as diferenças engendram os termos e não o contrário (MERLEAU-PONTY, 2004, p. 67, 72). O sistema opositivo da linguagem faz com 
que os signos possuam uma "relação lateral" entre si, de modo que ela se torna oblíqua e autônoma, significando indireta e alusivamente. Assim, a linguagem não traduz significações dadas, limitando-se apenas pelo funcionamento opositivo de seus signos. A relação lateral entre os signos torna a linguagem um "movimento de diferenciação e articulação" (MERLEAU -PONTY, 2004, p. 71). Dessa forma, cada significação aparece já como algo a ser superado, como a ocasião ou o apoio para uma nova significação. O sentido do gesto expressivo é assim "um sentido em gênese", uma instituição ou um advento que é ao mesmo tempo já a promessa de uma nova significação. O mesmo acontece na literatura, na qual o rearranjo das significações cristalizadas traz uma significação inédita, mas tal que esta era já anunciada ou uma promessa dos livros anteriores. Cada novo livro abre e exige uma retomada futura. A palavra assim não substitui uma significação pré-determinada. Ao contrário, ela "tateia em torno de uma intenção de significar" (MERLEAU-PONTY, 2004, p. 75). A fala não conhece de antemão a significação que quer atingir, senão que se deixa investir por certa acumulação tácita e implícita dos arranjos diacríticos, pelo excesso do que há por dizer sobre o que já foi dito. Se o falante tem por vezes a impressão de que as significações já estão prontas e ele somente as reproduz ou apenas troca os signos de um pensamento que pode existir independente deles, isso se deve às virtudes da própria linguagem. Esta permite que um sentido instituído se cristalize na cultura, podendo ser então retomado por todos os falantes. A instituição, fundação ou estabelecimento de uma significação verdadeiramente nova não se guia por um pensamento em relação ao qual se escolheria um signo adequado, mas graças ao "sentido lateral ou oblíquo que se insinua entre as palavras" (MERLEAU-PONTY, 2004, p. 75), ao "fundo de silêncio" ou "silêncio falante" que cada palavra porta. A fala verdadeiramente nova é, em sua "fase de estabelecimento", certa acumulação ou excesso ${ }^{33}$, "uma intenção de significar" que, quando se institui, "encerra [...] em um único ato todo um devir de expressão” (MERLEAU-PONTY, 2004, p. 110).

$33 \quad$ O termo "excesso" é usado também na Fenomenologia da percepção para se referir a essas mesmas virtualidades ou possibilidades outras que acompanham cada expressão ou significação. 
O mesmo se daria na pintura. Em cada quadro, o pintor expressa uma metamorfose ou "deformação coerente" do mundo, e de tal modo que cada pintura se faz segundo determinado estilo, um "sistema de equivalências" que se expressa em cada quadro do pintor, a partir do momento em que ele encontrou sua própria voz. Em seu trabalho, o pintor concentra o sentido ainda disperso na percepção e o faz convergir em um tipo definido de expressão. Ele não retira sua pintura de sua esfera íntima, mas de suas relações com o mundo. Cada fragmento do mundo, argumenta Merleau-Ponty, "contém todas as espécies de figuras do ser" (MERLEAU-PONTY, 2004, p. 86). Desse modo, a relação entre a lã na tela e a lã real não é feita pelo sujeito, mas pela "lógica alusiva do mundo" (MERLEAU-PONTY, 2004, p. 87). Esta permite, por exemplo, que Renoir pinte o riacho das Lavadeiras interrogando o mar. Cada quadro é também uma interpretação do sistema diacrítico do mundo; o riacho das Lavadeiras, uma "maneira de interpretar a substância líquida" (MERLEAU-PONTY, 2004, p. 86). O mundo seria assim o "princípio das equivalências" (MERLEAU-PONTY, 2004, p. 85) por meio das quais o pintor realiza sua obra. Como "'deformação coerente' imposta ao visível" (MERLEAU-PONTY, 2004, p. 112), cada quadro possui certa "irradiação muda" ou "acumulação tácita e implícita". Tal como a percepção nunca é acabada, oferecendo um mundo que, ao englobar, ultrapassar e anunciar-se em cada perspectiva, está sempre em vias de ser expresso, assim também a pintura oferece um mundo "por pintar" ou "por desenhar". Dessa maneira, as obras "rivalizam" entre si e o esforço de expressão é sempre recomeçado. O mundo não é um modelo interior, mas tal que se anuncia em cada estilo, em cada tela. Ele é um sistema diacrítico que solicita novas configurações.

Segundo Carbone, a fecundidade da expressão seria fruto da relação entre língua e fala:

a transcendência que opera na linguagem [...] age precisamente em virtude da interação da fala com a língua, isto é, em virtude da implicação recíproca dos dois elementos que a compõem; escolhe-se no patrimônio sedimentado de signos e de significações estes significantes, graças ao encontro dos quais germina um sentido novo que estava implicado neles e que contudo os ultrapassa, e ultrapassa igualmente a intenção significativa do sujeito falante. (CARBONE, 1993, p. 410, 411) 
Todavia, Merleau-Ponty parece localizar a produtividade da expressão em uma espontaneidade, um interesse ou uma "iniciativa própria" vinda do corpo.

Em A linguagem indireta, Merleau-Ponty pergunta pela "origem da significação", no sentido, porém, de como o estilo do artista pode ser a expressão de uma maneira de relacionar-se com o mundo, como quadros de diferentes culturas reproduzem os mesmos traços sem que seus autores tenham se conhecido, como a linguagem é o ponto mais alto de um poder de significar já presente na pintura.

Não se trata de compreender de que modo significações, ou ideias, ou procedimentos dados vão ser aplicados a esse objeto, que figura imprevista o saber irá tomar nessa circunstância. Trata-se antes de compreender de que modo esse objeto, essa circunstância passam a significar, e sob quais condições. (MERLEAU-PONTY, 2002, p. 85)

É preciso compreender como algo se institui, ultrapassando os momentos anteriores, as falas sedimentadas, as obras já feitas. Por um lado, essa interrogação é respondida por meio da ideia de que o corpo é um "sistema de sistemas" (MERLEAU -PONTY, 2002, p. 106), de modo que o corpo, enquanto traz em si o esquema do mundo (Cf. MERLEAU-PONTY, 2004, p. 99), possuiria determinado estilo, determinadas possibilidades perceptivas por meio das quais ele se relacionaria com o mundo. No entanto, Merleau-Ponty assegura que o corpo, isto é, a possibilidade de os autores possuírem corpos semelhantes, com as mesmas possibilidades perceptivas, não explica completamente porque obras de diferentes origens expressam o mesmo estilo. Segundo Merleau-Ponty, o "próprio do corpo humano é não comportar natureza" (MERLEAU-PONTY, 2002, p. 108; grifo meu). Embora Merleau-Ponty afirme uma "universalidade do sentir", esta é moldada pela cultura assim que a criança aprende a falar; no nível linguístico, a percepção "projeta no mundo a assinatura de uma civilização" (MERLEAU-PONTY, 2002, p. 96). O que poderia, entretanto, fundamentar a "unidade do estilo humano" (MERLEAU-PONTY, 2004, p. 101)?

Por um lado, há uma "universalidade do sentir", a qual confere aos diversos grupos humanos possibilidades sensoriais 
e sinestésicas semelhantes - embora essas possibilidades sejam logo moldadas pela cultura em que cada indivíduo está inserido. Por outro lado, o corpo, os sentidos, as equivalências sensoriais são atravessados pelo movimento temporal, pela intencionalidade, por um esforço de expressão que se realiza como "transgressão intencional", isto é, como superação de cada perspectiva dada, excesso de sentido, e concomitante retomada dos momentos passados.

Ao tratar do gesto humano - o qual diz respeito também à pintura e à fala, os quais são denominados nos textos como "gestos expressivos" e "gesticulação cultural" —, Merleau-Ponty afirma que o próprio do gesto é "significar para além de sua simples existência de fato", que ele "vale mais do que sua simples presença" (MERLEAU-PONTY, 2004, p. 107, 100). Isso acontece porque a "expressão primordial [...] longe de esgotar-se no instante em que ocorreu, abre um campo, inaugura uma ordem, funda uma instituição ou uma tradição..." (MERLEAU-PONTY, 2002, p. 106). O sentido do gesto expressivo é um "sentido em gênese", de modo que algo expresso, no momento mesmo em que se realiza, reclama já sua transformação (Cf. MERLEAU-PONTY, 2002, p. 111, 110). O que torna possível que a expressão opere de tal maneira? O que possibilita que a percepção, o gesto, enfim, toda forma de expressão não se consuma num agora, indo sempre "além" de cada ato realizado? Isso parece ocorrer porque o expresso não se imobiliza numa espécie de eternidade, senão que, ao contrário, "exige a sucessão, tem necessidade dela" (MERLEAU-PONTY, 2002, p. 111; grifo meu).

Merleau-Ponty argumenta que, assim como o corpo "domina sua dispersão e impõe seu monograma a tudo o que faz", de modo análogo a unidade do estilo humano "concentra os gestos de todos os pintores numa única tentativa" (MERLEAU-PONTY, 2004, p. 101). A posse corporal do espaço é um "esforço" (MERLEAU-PONTY, 2004, p. 102) comparável ao "esforço" dos gestos dos pintores. Assim, as diferentes pinturas "convergem pelo fato único de serem esforços de expressão" (MERLEAU-PONTY, 2004, p. 102), da mesma forma que o corpo toma posse do espaço por seu esforço. O que está na base 
dessa analogia é a ideia de sucessão ou de "transição perceptiva de um momento ao outro" (MERLEAU-PONTY, 2004, p. 101). Nesse sentido, diz Merleau-Ponty:

A dominação do uno sobre o múltiplo na história da pintura, como a que encontramos no exercício do corpo ao perceber, não absorve a sucessão numa eternidade: exige ao contrário a sucessão, precisa dela ao mesmo tempo que a funda em significação. (MERLEAU -PONTY, 2004, p. 102)

Se o gesto expressivo é um sentido em gênese, se toda instituição traz já a promessa de uma continuidade, se a pintura e a percepção dominam seus respectivos múltiplos, sua dispersão inicial, é porque todos eles são esforços de expressão que convergem em um determinado sentido. Merleau-Ponty define o fenômeno de expressão como "um movimento sem outro guia além de sua própria iniciativa e que, no entanto, não escapa para fora de si mesmo, se cruza e se confirma de longe em longe" (MERLEAU-PONTY, 2004, p. 106). Retomando Hegel, trata-se de dizer que o ato de expressão é "uma marcha que cria ela mesma o seu curso e torna a voltar a si mesma" (MERLEAU-PONTY, 2004, p. 106). A operação expressiva é o próprio movimento de transcendência, de sucessão ${ }^{34}$, de transição, um "ir além" ou "ir mais longe" que se refaz no momento mesmo em que uma significação se institui. Desse modo, não se tratava de fazer uma simples analogia entre os diferentes esforços de expressão. Se o homem é o portador privilegiado da transcendência (Cf. MERLEAU-PONTY, 2004, p. 104), então se entende que "é a operação expressiva, iniciada pela menor percepção, que se amplifica em pintura e em arte" (MERLEAU-PONTY, 2004, p. 102). Um só movimento ou esforço liga todos os atos de expressão e ele inicia-se na percepção, no momento em que um corpo emerge no mundo.

$34 \quad$ A sucessão de que tratam os textos intermediários guarda um sentido diverso da sucessão apresentada na Fenomenologia da percepção. Não se trata mais de um perfilamento de instantes presentes nos quais se dá uma coincidência de si consigo, o Cogito tácito. O sistema diacrítico exclui qualquer tipo de identidade prévia, apresentando-se como uma configuração na qual cada termo significa sua diferença em relação aos outros. Há sucessão quando há passagem de um arranjo a outro, não de uma identidade à outra. 
Esse esforço de expressão é o próprio movimento temporal ou intencional. A "universalidade do sentir" não diz respeito somente aos órgãos dos sentidos, os quais seriam semelhantes, teriam os mesmos poderes de apreensão em diferentes raças e culturas, mas ao movimento intencional, temporal (um mesmo esforço de expressão) que integraliza, articula a sinestesia corporal (suas equivalências). É este modo de ser homem, isto é, de ser temporal, que reúne diferentes culturas e diferentes períodos da história. Segundo a Fenomenologia da percepção, os sentidos por si sós não me fariam ser no mundo ${ }^{35}$; é preciso pois que eles sejam atravessados, perpassados pelo movimento intencional, temporal. É esse esforço, isto é, a necessidade imperativa do "ir além" temporal, no qual se dão as "transgressões intencionais", o ressoar de sentidos, a frequentação de outras possibilidades perceptivas em cada tomada atual, que reúne as diferentes tentativas artísticas de diferentes civilizações, pois ele integra todos os homens em uma mesma transcendência: a temporalidade, a intencionalidade, isto é, o esforço de expressão.

É preciso notar que, ao fundar a ordem cultural na percepção, Merleau-Ponty está defendendo que ambas as esferas funcionam graças a um mesmo esforço ou mesma transcendência. Não se trata, portanto, de simples analogia, ou de certa semelhança formal entre as diferentes modalidades da expressão. A pintura e as outras artes amplificam a operação expressiva, apresentam um estilo de exprimir, porque a percepção ela mesma já estiliza (Cf. MERLEAU-PONTY, 2004, p. 84): "Qualquer percepção, qualquer ação que a suponha, em suma, qualquer uso humano do corpo já é expressão primordial" (MERLEAU -PONTY, 2004, p. 99). A percepção oferece uma reconstituição dos dados sensíveis que leva em conta dar uma resposta

35 "as funções sensoriais por si sós não me fazem ser no mundo" (MERLEAU-PONTY, 2006, p. 229). Para que algo se manifeste ao corpo, é preciso que os sentidos não sejam simples instrumentos, mas atravessados pelo movimento temporal, isto é, já intencionalidade operante. Para que haja ser no mundo, uma visão pré-objetiva, isto é, que algo apareça segundo uma perspectiva, é preciso que as funções sensoriais não sejam somente instrumentos do corpo (ou do sujeito), mas a realização mesma (ou modalizações) da intencionalidade (temporalidade). 
à solicitação que esses mesmos dados exigem; é nesse sentido que a "pintura existe antes da pintura" (MERLEAU-PONTY, 2004, p. 84). Desse modo, pode-se entender algumas expressões a respeito do corpo, como a que diz que ele é um "sistema de sistemas" ou quando se diz que o corpo traz em si o esquema do mundo. Ele é um sistema de equivalências sensoriais cujo impulso de ir além é a transcendência dos instantes temporais.

Em Um inédito de M. Merleau-Ponty (1951), a universalidade da história aparece como tema. Embora tenha sido publicado só em 1962, esse texto foi redigido e enviado a Martial Guéroult no mesmo período em que este preparava a relação dos títulos referentes à candidatura de Merleau-Ponty ao Collège de France. Por isso, supõe-se que ele tenha sido escrito por volta de 1951. Merleau-Ponty argumenta então que não se pode rejeitar como estrangeiras as aventuras da história, posto que as ações e as produções humanas compõem um "único drama", porque a vida humana é "universal" (MERLEAU-PONTY, 2000a, p. 46). Essa universalidade, porém, não significa um racionalismo dogmático, o qual teria por intuito eliminar a contingência histórica ao supor um espírito absoluto por trás das coisas. A universalidade é antes a de um "único tecido" que reúne todos os empreendimentos humanos. Esse tecido único ou denominador comum diz respeito a que todas as culturas são "sistemas coerentes de símbolos" (MERLEAU-PONTY, 2000a, p. 47). Isso possibilita que os aspectos de uma cultura relacionem-se entre si e com os aspectos de outras culturas, de forma que se encontra uma pluralidade de seres que se reconhecem como "semelhantes". Mas o que torna possível essa universalidade, isto é, que todas as culturas sejam sistemas coerentes de símbolos? O que é comum a tudo, o que transparece através do movimento da história é, afirma Merleau-Ponty, o "homem transcendental" (Cf. MERLEAU-PONTY, 2000a, p. 47). Ao especificar o que seja esse "homem transcendental", o texto esclarece que se trata de certa "luz natural", um Logos do mundo percebido. Esse Logos é o fenômeno de expressão, a "boa ambiguidade" que supera as dicotomias da filosofia clássica e mesmo as da Fenomenologia da percepção, uma espontaneidade que "reúne em um único tecido a pluralidade das mônadas [seres], o passado e o presente, 
a natureza e a cultura" (MERLEAU-PONTY, 2000a, p. 48). A "boa ambiguidade" é a transcendência dos sistemas diacríticos, por meio da qual o mundo sensível individual é sublimado na linguagem, no mundo cultural, quando o mundo anônimo individual (perceptivo) torna-se uma "universalidade reconhecida" (MERLEAU-PONTY, 2002, p. 176). No sistema de cada cultura se apresenta um mesmo fenômeno de expressão, uma mesma espontaneidade, a qual as torna sistemas coerentes de símbolos. Essa espontaneidade articula os momentos do tempo, reúne passado e presente, de forma que ela é a espessura temporal do sensível, e não um espírito absoluto por trás das coisas. Ela articula ainda natureza e cultura, revelando-as como modalidades de um mesmo fenômeno, como sistemas semelhantes atravessados pela "boa ambiguidade" do fenômeno de expressão. $\mathrm{O}$ "homem transcendental", elo comum de todos os homens, diz respeito, portanto, à temporalidade, à intencionalidade, isto é, ao mesmo esforço de expressão que atravessa e conduz todos os homens, culturas ou civilizações; de maneira que é nele que se deve encontrar a unidade do estilo humano. "A constatação dessa maravilha", termina Merleau-Ponty, "seria a metafísica mesma" (MERLEAU-PONTY, 2000a, p. 48). O desvelamento da espontaneidade do fenômeno de expressão permite que se ultrapasse a "má ambiguidade" entre interioridade e exterioridade característica da filosofia clássica e em parte reproduzida na Fenomenologia da percepção, e mostra-se como a chave ontológica para a compreensão da pluralidade das manifestações humanas. O a priori da correlação dá lugar à transcendência dos gestos e dos signos. A produtividade diacrítica da linguagem encontra-se também na apreensão perceptiva, de modo que esta se revela um transcender de configurações ou de campos não mais dependente exclusivamente das equivalências sensoriais, embora estas também contem no conjunto. Segundo $A$ linguagem indireta e as vozes do silêncio, é um mesmo esforço de expressão, isto é, uma mesma espontaneidade que articula as diferentes manifestações humanas ao longo da história.

Um inédito de $M$. Merleau-Ponty também reapresenta a ideia de que a experiência se inaugura por meio de um pacto originário: "O sujeito da percepção não é um pensador absolu- 
to, ele funciona segundo a execução de um pacto, realizado em nosso nascimento, entre nosso corpo e o mundo (...)" (MERLEAU-PONTY, 2000a, 404; grifo meu). Contudo, o pacto originário tem aqui um sentido diverso daquele da Fenomenologia da percepção. Ele diz respeito agora à ebulição ou ao emergir do corpo em uma configuração, em um sistema opositivo dos dados sensíveis. O pacto não é mais a abertura do percebido e de tudo o que vem a ser extraído dele, mas a abertura do campo humano, o qual é apenas uma parte do sensível total.

Em face do sistema opositivo das coisas, o corpo opera uma reorganização, uma tomada, a qual não abarca a totalidade do mundo. Tal reorganização implica a solicitação das coisas, cuja disposição exige do corpo uma resposta, e ao mesmo tempo certo esforço, certo interesse do corpo em visar algo no mundo. Há uma relação de duplo sentido entre passividade e atividade. Por isso, o ato de expressão não se restringe a prodigalizar um poder expressivo acumulado na língua, como se as significações estivessem em um inconsciente da língua, mas evidencia o "poder que os falantes têm de ultrapassar os signos em direção ao sentido" (MERLEAU-PONTY, 2004, p. 116; grifo meu). O mesmo vale para o corpo: tão somente a configuração dos dados sensíveis não teria como fazer o corpo movimentarse no mundo. É preciso, da mesma forma, que seu olhar ataque o mundo (Cf. MERLEAU-PONTY, 2004, p. 84), que os olhos, por exemplo, sejam "meios de interrogar" (MERLEAU-PONTY, 2004, p. 112), também inquirindo das coisas uma resposta.

\section{Bibliografia:}

Bibliografia principal

MERLEAU-PONTY, Maurice. Le monde sensible et le monde de l'expression. Cours au Collège de France, Notes, 1953. Genève: Metis Presse, 2011.

MERLEAU-PONTY, Maurice. La prose du monde. Paris: Gallimard, 1992.

MERLEAU-PONTY, Maurice. A prosa do mundo. Trad.: Paulo Neves. Edição e prefácio de Claude Lefort. São Paulo: Cosac\&Naif, 2002.

MERLEAU-PONTY, Maurice. L'oeil et l'esprit. Paris: Gallimard, 1996. 
MERLEAU-PONTY, Maurice. O olho e o espírito. $1^{\text {a }}$ ed. Trad.: Paulo Neves e Maria Ermantina Galvão Gomes Pereira. São Paulo: Cosac \& Naify, 2004.

MERLEAU-PONTY, Maurice. Merleau-Ponty à la Sorbonne: résumé de cours (1949-1952). Cynara, 1988.

MERLEAU-PONTY, Maurice. Notes de Cours. Paris: Gallimard, 1996.

MERLEAU-PONTY, Maurice. Parcours. Lagrasse: Verdier, 1997.

MERLEAU-PONTY, Maurice. Parcours deux. Lagrasse: Verdier, 2000a.

MERLEAU-PONTY, Maurice. Phénoménologie de la perception. Paris: Gallimard, 1995.

MERLEAU-PONTY, Maurice. Fenomenologia da percepção. Trad.: Carlos Alberto Ribeiro de Moura. São Paulo: Martins Fontes, 2006.

MERLEAU-PONTY, Maurice. Sens et non sens. Paris: Nagel, 1966.

MERLEAU-PONTY, Maurice. Signes. Paris: Gallimard, 1985.

MERLEAU-PONTY, Maurice. Signos. Trad.: Maria Ermantina. São

Paulo: Martins Fontes, 1991.

Bibliografia secundária

ALMEIDA, Guido. "Sobre a fenomenologia da linguagem".

In: Manuscrito: Revista de Filosofia, vol. V, n ${ }^{\circ} 2 \mathrm{abr} / 82$

- UNICAMP, p. 77-89.

BIMBENET, É. Nature et Humanité. Le problème antropologique dans l'oeuvre de Merleau-Ponty. Paris: Vrin, 2004.

CARBONE, M. La visibilité de l'invisible. Hildesheim: OLMS, 2001.

CARBONE, M. "La dicibilité du monde. La période intermédiaire de la pensée de MerleauPonty à partir de Saussure". In: VV.AA. Merleau -Ponty - le philosophe et son langage. Paris: Vrin, 1993.

CHAUI, M. Experiência do pensamento: ensaios sobre a obra de Merleau-Ponty. São Paulo: Martins Fontes, 2002.

DASTUR, Françoise. La phénomènologie en questions: langage, altérité, temporalité, finutude. Paris: VRIN, 2004.

DASTUR, Françoise. Chair et language: essais sur Merleau-Ponty. La versanne: Encre marine, 2001.

DESANTI, J. T. "Merleau-Ponty et la décomposition de l'idealisme". La Nouvelle Critique, n.37, 1951.

FERRAZ, Marcos S. A. Fenomenologia e ontologia em Merleau-Ponty. São Paulo: Papirus, 2009. 
MOURA, A. C. M. Racionalidade e crise. São Paulo: Discurso Editorial e Editora UFPR, 2001.

MOUTINHO, Luiz Damon S. Razão e experiência. São Paulo: UNESP, 2006.

MOUTINHO, Luiz Damon S. "Merleau-Ponty e a 'filosofia da consciência"'. In: Merleau-Ponty. Revista Dois pontos: Curitiba, São Carlos, vol. 9, n. 1, abril de 2012 .

MÜLLER, M. J. Merleau-Ponty, acerca da expressão. Porto Alegre: Edipucrs, 2001.

SAUSSURE, F. Curso de linguística geral. São Paulo: Editora Cultrix, 2006. 